\title{
Comparison and Measurement of Serum Levels of Magnesium (Mg) \&Zinc (Zn) In Patients with Non- Proliferative Diabetic Retinopathy (NPDR) \&Proliferative Diabetic Retinopathy (PDR)
}

\author{
Dr. J.J.Kuli ${ }^{1}$,Dr.Deepanjan Ghosh ${ }^{1}$. \\ ${ }^{1}$ (Department of Ophthalmology,Assam Medical College,Dibrugarh,India)
}

\begin{abstract}
:
Purpose: To evaluate the serum levels of Magnesium $(\mathrm{Mg})$ and Zinc $(\mathrm{Zn})$ in patients with NPDR and PDR and their statistical comparison.

Setting: Assam Medical College \&Hospital,Dibrugarh.

Study design: Comparative, Non-randomized study.

Patients and Methods: The serum levels of $M g$ and $Z n$ were analyzed by using Calmagite method $(M g)$ and Colorimetric methods respectively $(\mathrm{Zn})$ in 15 patients with Moderate to severe Non Proliferative Diabetic Retinopathy (NPDR) and 15 patients with Proliferative Diabetic Retinopathy (PDR), hence totaling 30patients. There were no controls in our study.

Results: There was a significant decrease in Magnesium levels noted in DM patients with PDR when compared to NPDR group. There was a gradual hypozincaemia noted with increasing spectrum of Diabetic severity.

Conclusion:The evaluation of $\mathrm{Mg}$ and $\mathrm{Zn}$ may indicate the severity of diabetic retinopathy.

Key words: Magnesium, Non Proliferative Diabetic Retinopathy,Proliferative Diabetic Retinopathy, Zinc.
\end{abstract}

\section{Introduction.}

Diabetes mellitus is a multi-factorial disease characterized by deficiency of insulin or resistance to insulin. Diabetic Retinopathy is one of the most common microvascular complications of diabetes, affecting $80 \%$ of patients over 20 years duration of diabetes.

Zinc is a metallo-enzyme which form Zn-enzyme complex. In diabetic retinopathy there is a disturbance of this vital trace element .Zinc plays an important role in insulin synthesis and storage of insulin which is secreted as zinc crystal. It helps in maintaining structural integrity of insulin .Zinc also plays a key role in the cellular antioxidative defense mechanisms.Zinc deficiency causes oxidative stress, which damages the cell irreversibly, producing or exacerbating some of the classical complications of diabetes.

Magnesium is a cofactor in the phosphorylation of glucose and in many other enzymatic reactions. Its deficiency drive in insulin resistance, carbohydrate intolerance, dyslipidemia and complications of diabetic retinopathy .Studies reported that the diabetes induced damage to the eyes is more likely to occur in magnesium deficient patients with insulin dependent diabetes mellitus and suggested hypomagnesemia as a possible risk factor in the development and progress of diabetic retinopathy.

We conducted this study to evaluate levels of zinc and magnesium in diabetic retinopathy patients to further clarify their role in the severity of this disease.

\subsection{AIMS \& OBJECTIVES:}

\section{Materials \& Methods.}

The aims of the study were:

1. To estimate the levels of serum magnesium \& Zinc in clinically diagnosed diabetes mellitus patients with non-proliferative diabetic retinopathy.

2. To estimate the levels of serum magnesium \& Zinc in clinically diagnosed diabetes mellitus patients with proliferative diabetic retinopathy.

3. To compare and analyze the levels of these parameters in above groups.

\subsection{SOURCE OF DATA:}

Clinically diagnosed cases of Diabetes Mellituswith Diabetic Retinopathy attending the Retina Clinic of Ophthalmology Department of AMCH,Dibrugarh. 


\title{
2.3 METHOD OF COLLECTION OF DATA:
}

15 patients with NPDR and 15 patients with PDR were included in the study and the following tests were done:

1. Fasting Blood Glucose (FBS).

2. Post Prandial Blood Glucose Level (PPBS).

3. Serum Magnesium Levels (Calmagite Dye Method)

4. Serum Zinc Levels (Colorimetric Method).

5. Serum Creatinine.

\subsection{INCLUSION CRITERIA:}

Cases clinically diagnosed Diabetes Mellitus ( Both Type $1 \&$ Type 2 DM ) with Non Proliferative Diabetic Retinopathy and another group with Proliferative Diabetic Retinopathy. Diabetes was diagnosed as per WHO diagnostic criteria. Retinopathy was categorized by fundus examination undermydriasis of both eyes using Indirect Ophthalmoscopy and Slit Lamp Biomicroscopywith $90 \mathrm{D}$ lensand confirmed by Fundus Fluorescein Angiography.

\subsection{EXCLUSION CRITERIA :}

1. Patients of Diabetes having Renal and Cardiovascular complications.

2. Patients on Diuretics.

3. Malabsorption or Chronic Diarrhea.

\subsection{STATISTICAL ANALYSIS:}

Statistical significance was analyzed by Students ' $t$ 'test and correlation between variables were studied by using Pearson's Correlation Coefficient test. "p" values less than 0.05 were considered significant.

\section{Results And Observations.}

\author{
Table 3.1:
}

Mean Age \& Duration Of Diabetes In Both Groups:

\begin{tabular}{|l|l|l|l|}
\hline & $\begin{array}{l}\text { NPDR } \\
(\mathrm{n}=15)\end{array}$ & $\begin{array}{l}\text { PDR } \\
(\mathrm{n}=15)\end{array}$ & P value \\
\hline AGE (In Years) & $54.86( \pm 10.11)$ & $55.93( \pm 11.50)$ & $\mathrm{p}=0.7894$ \\
\hline $\begin{array}{l}\text { Duration Of Diabetes } \\
\text { (In Years) }\end{array}$ & $7.26( \pm 3.71)$ & $11.13( \pm 5.57)$ & $\mathrm{p}=0.03485$ \\
\hline
\end{tabular}

Table 3.2:

Mean Pattern Of Blood Glucose \& Serum Creatinine Levels:

\begin{tabular}{|l|l|l|l|}
\hline & $\begin{array}{l}\text { NPDR } \\
(\mathrm{n}=15)\end{array}$ & $\begin{array}{l}\text { PDR } \\
(\mathrm{n}=15)\end{array}$ & P value \\
\hline Fasting Blood Glucose(mg/dl) & $153.2( \pm 79.53)$ & $172.73( \pm 113.34)$ & $\mathrm{P}=0.58963$ \\
\hline PPBG(mg/dl) & $251.26( \pm 127.45)$ & $269.76( \pm 189.28)$ & $\mathrm{P}=0.75619$ \\
\hline SerumCreatinine $(\mathrm{mg} / \mathrm{dl})$ & $1.02( \pm 0.16)$ & $1.14( \pm 0.21)$ & $\mathrm{P}=0.12038$ \\
\hline
\end{tabular}

Table 3.3:

Serum Magnesium Levels In NPDR \& PDR Groups:

\begin{tabular}{|l|l|l|}
\hline $\begin{array}{l}\text { Serum Magnesium } \\
(\mathrm{N}=1.8-2.5 \mathrm{mg} / \mathrm{dl})\end{array}$ & NPDR & PDR \\
\hline Range $($ Min-Max $) \mathrm{mg} / \mathrm{dl}$ & $2.12-2.52$ & $2.02-2.36$ \\
\hline Mean $\pm \mathrm{SD}$ & $2.32( \pm 0.12)$ & $2.20( \pm 0.11)$ \\
\hline $\mathrm{p}=0.01152$ & \multicolumn{2}{|l}{} \\
\cline { 2 - 3 }
\end{tabular}


Table 3.4:

Serum Zinc Levels In NPDR \& PDR Groups:

\begin{tabular}{|l|l|l|}
\hline $\begin{array}{l}\text { Serum Zinc } \\
(66-110 \mu \mathrm{g} / \mathrm{dl})\end{array}$ & NPDR & PDR \\
\hline Range (Min-Max) $\mu \mathrm{g} / \mathrm{dl}$ & $52-96$ & $25.9-76$ \\
\hline Mean \pm SD & $69.75( \pm 11.95)$ & $50.81( \pm 11.80)$ \\
\hline $\mathrm{p}=0.00016$ & \multicolumn{2}{|l}{} \\
\cline { 2 - 3 }
\end{tabular}

Table 3.5:

Serum Zinc Levels According To Duration Of Disease:

\begin{tabular}{|l|l|l|}
\hline \multirow{2}{*}{ Duration of disease } & Serum Zinc levels $(\mu \mathrm{g} / \mathrm{dl})$ & \multicolumn{2}{|l|}{} \\
\cline { 2 - 3 } & NPDR & PDR \\
\hline 1 to 3 yrs & $70.55( \pm 2.19)$ & $50.6( \pm 23.19)$ \\
\hline 4 to 6 yrs & $68.95( \pm 18.94)$ & $58.95( \pm 0.07)$ \\
\hline 7 yrs and above & $69.93( \pm 10.69)$ & $51.19( \pm 11.84)$ \\
\hline
\end{tabular}

\section{Discussion}

Diabetic retinopathy is a common microvascular complications of both type I and type II diabetes mellitus that can severely impair visual acuity, eventually leading to blindness. The prevalence of retinopathy increases with the duration of diabetes.

In the present study, the mean duration of diabetes in the NPDR group was found to be $7.26( \pm 3.71)$ yrs while in PDR it was $11.13( \pm 5.57)$ yrs.

The serum levels of Magnesiumin both the groups were within normal limits but there was a statistically significant difference among the patients with different stages of retinopathy $(\mathrm{p}<0.05)$.

The more advanced the stage of retinopathy, the lower is the serum magnesium concentration. These findings are consistent with the study of Valk et al, who observed a significant association between plasma $\mathrm{Mg}$ concentration and the development of background retinopathy but did not state the association with the severity of retinopathy. Consequently, hypomagnesemiaseem to be as a possible risk factor in the development and progress of diabetic retinopathy. Hypomagnesemia was more pronounced in case of advanced retinopathy and diabetic maculopathy.

Hatwal A et al reported that serum Mg levels among the cohort with diabetes had an inverse correlation with the degree of retinopathy.

Hypozincaemia was seen in all diabetic subjects, but the decrease in levels was more in the group with proliferative diabetic retinopathy $(69.75 \pm 11.95$ vs $50.81 \pm 11$.80in NPDR $)$ and the decrease in serum levels between the two groups of patients was highly significant $(\mathrm{p}<0.05)$.

In their study ,Garg V et al and Kinlaw WB et al have showed the correlation of hypozincemia with diabetes mellitus and its serum levels in diabetic retinopathy but they have not reported its relation with the severity of diabetic retinopathy.

The cause of decreased serum zinc levels in diabetic retinopathy is may be due to increase in urinary loss.

\section{Conclusion.}

There is a significant decrease in both Magnesium and Zinc levels in different stages of diabetic retinopathy.So, therapeutic intervention to increase dietary intake and oral supplementation of Zinc and Magnesium may be advantageous.It may be prudent in clinical practice to periodically monitor plasma Magnesium and Zinc concentrations in diabetic patients in order to halt the progression of this commonmicrovascular complication of diabetes.

\section{References}

[1]. Kertis PJ, Johnson TM, Ed(2007).Evidenced Based Eye. (Philadelphia, PA:Lippincott Williams and Wilkins). ISBN O-7817-6964-7

[2]. Candilish, D.J., 2000. Minerals, J. Am. Coll. Nutr., 17:286-310.

[3]. Chausmer AB. Zinc, insulin and diabetes. J Am College Nutr. 1998; 17: 109-14.

[4]. McNair P, Kiilerich S, Christiansen C, Christiansen M, Madsbad S, Transbol I: Hyperzincuria in insulin treated diabetes mellitus-its relation to glucose homeostasis and insulin administration. ClinicaChimicaActa 112:343-348, 1981.

[5]. Grafton, G. and Baxter, M. A., J. Diab. Complications, 1992, 6, 143-149.

[6]. Valk HW, Hardus PLLJ, Van Rijn HJM, Erkelens DW. Plasma magnesium concentration andprogression of retinopathy. Diabetes Care 1999; 22(5):864-865.

[7]. Hatwal A, Gujral AS, Bhatia RPS, Aggarwal JK, Bajpai HS. Association of hypomagnesemia with diabetic retinopathy. ActaOphthalmol 1989;67:714-16 
[8]. Garg V, Gupta R, Goal R: Hypozincemia in diabetes mellitus. J.A.P.I. 42:720-721, 1994.

[9]. Kinlaw WB, Levine S, Morley J, Silvis S, McClain C: Abnormal Zn metabolism in type II diabetes mellitus. Am J Med 1983:75:273-277, 1983. 